tance in France. $V$. vinifera fruits contain principally monoglucosides; the American varieties have, in addition, diglucosides (no other sugars have been detected). Acylated pigments are often present, with caffeic and $p$-coumaric acids as the combined acids.

A paper on enzymatic browning by J.W. Corse (Western Regional Research Laboratory, U.S. Department of Agriculture, Albany, Calif.) opened the second half of the symposium. The enzymes involved are copper-containing oxidases which are difficult to isolate and often appear to be mixtures. Molecular weights are of the order of 120,000 with perhaps four copper atoms; in some cases, the copper appears to be cuprous. The browning reaction occurs stepwise. After formation of a catechol group by introduction of a hydroxyl group, oxidation to $o$-quinones occurs. Finally, the latter polymerize non-enzymatically to dark substances, but the structure of the products is still not clear. Substrates in deciduous fruits include chlorogenic acid and related compounds. In attempts to control browning, physical methods and chemical agents have been abandoned in favour of a biochemical approach. $O$-Methyl transferase has been found to convert the catechol group to the browning-resistant guaiacyl group.

The role of phenolics in disease resistance in plants was discussed by J. Kuc' (Purdue University, Lafayette, Ind.). Increased production of chlorogenic and caffeic acids and a variety of aromatics occur both in response to disease and to wounding, the actual amount produced varying with the agent causing injury. These higher. than-normal concentrations, which are present especially on plant surface or at infection sites, inhibit microbial growth. The mechanisms by which miero-organisms bring about this increased production are varied and not yet completely understood. In general, they appear to be due to specific alterations in the metabolic pathways of both host and micro-organism. Resistance may then result from a shift in the very delicate metabolic balance.

The symposium concluded with a paper by T. Kosuge (University of California, Davis) outlining the present state of knowledge of the biosynthesis of the phenolic acids and coumarins which have been shown to accumulate in diseased tissue. Very few investigations of their biosynthesis in diseased plant tissues have been made, but considerable work has been done on healthy tissues. The acetate and shikimic acid pathways, which occur in higher plants, appear to be involved in the production of such compounds. The Proceedings of the symposium will be published in due course.

The officers for the Plant Phenolics Group of North America elected for the present year are: President, Dr. Margaret K. Seikel; Vice-president, Dr. Bernard J. Finkle; Secretary-Treasurer, Dr. V. C. Runeckles (Imperial Tobacco Co. of Canada, Ltd., Montreal, Canada).

Margaret K. Seiket.

\title{
PROBLEMS OF NOISE
}

$A^{s}$ long ago as 1948 the British Standards Institution published a code of practice entitled Sound Insulation (Houses, Flats and Schools) (CP 3. Ch. 3; 1948). It had, of course, been a problem long before this, but since the Second World War the incidence of noise, in the home, in industry and out of doors, on the human being, has grown to be a matter not only of psychological but latterly of medical concern. That code tackled the problem of noise of both indoor and outdoor origin. It was largely concerned with means of reducing noise by appropriate siting, positioning and screening of windows in buildings. It included data of noise reduction values in 'phons' for different kinds of windows, open or shut. A revised B.S. Code (Ch. 3; 1960), entitled Sound Insulation and Noise Reduction, followed. In the same year came the official Noise in Factories (Factory Building Studies, No. 6, H.M. Stationery Office, I960); L. L. Beranek's Noise Reduction (McGraw-Hill, 1960), and a paper by D. E. Broadbent on "Effects of Noise Reduction in a. Work Situation" (Occupational Psychology, April 1960). The last-mentioned author, who is director of the Medical Research Council Applied Psychology Research Unit, is also responsible for a more recent booklet, Noise in Industry, No. 6 in the series Ergonomics for Industry, prepared jointly by the Department of Scientific and Industrial Research Information Division and Warren Spring Laboratory*.

Undue noise is a matter which, in these modern days, affects us all in a great variety of ways, wherever we may be and whatever we are doing. On relaxed occasions it may be encouraged by certain members of the younger generation, abhorred by others more mature. But in day-to-day industrial occupations, it is quite another matter. There are three main reasons, as the author shows: ". . p people do not like it, it damages their hearing and it has a bad effect on their working efficiency". These three effects are not necessarily interrelated. As he says: ". . . a noise which is very annoying may not be loud enough to damage hearing, or make people work less

* Department of Scientific and Industrial Research. Ergonomics for Industry, No. 6. Noise in Industry. By D. E. Broadbent. Pp. 16. (London:
H.M. Stationery Office, obtainable (free) from D.S.I.R. Warren Spring Laboratory, Stevenage, Herts, 1964.) well. On the other hand, there is the rather alarming possibility that noises which do not annoy people at all may quite often damage their hearing or impair their efficiency. It is important therefore to distinguish the various effects from one another and not to assume that all is well just because the workers in a noisy factory seem to be contented". Thus the theme of this booklet is to alert us to the effects, direct or more dangerously insidious, which noise may have on people at work and, it may be added, by inference in social environments where sometimes noise is cultivated for its own sake.

In modern measurements of sound, two technical terms are at present used. 'Cycles per second' (c/s) is the unit used to measure frequency. The 'decibel' (dB) measures the intensity. "The loudest sounds we may meet have an intensity of more than a million million times the intensity of the faintest sound we can hear. A scale of decibels takes this into account." The scale is logarithmic. Proportional changes in intensity are covered by the same number of units. Thus a ten-fold increase, 1-10, 10-100, $100-1,000$, etc., is represented by a change of $10 \mathrm{~dB}$. Impressive examples are given: $135 \mathrm{~dB}$ hydraulic press at $3 \mathrm{ft} . ; 105 \mathrm{~dB}$ train whistle at $50 \mathrm{ft}$.; $95 \mathrm{~dB}$ automatic lathe at close range; $75 \mathrm{~dB}$ office machines between desks; $65 \mathrm{~dB}$ speech at 3 or $4 \mathrm{ft}$.; $20 \mathrm{~dB}$ whisper at $4 \mathrm{ft}$.; and $0 \mathrm{~dB}$ threshold of hearing at $1,000 \mathrm{c} / \mathrm{s}$. "It should also be noted that the smallest change appreciated by the ear is about $1 \mathrm{~dB}$ where the change is in a faint sound or in a loud sound. $\mathrm{dB}$ figures are usually quoted with roference to an arbitrary zero-actually 0.0002 dynes $/ \mathrm{cm}^{2}$-which is approximately the faintest sound we can hear at, $1,000 \mathrm{c} / \mathrm{s} . "$

This publication, although relatively brief, is convineing in its argument, supporting data, and message. The serious effects of noise on the ear, and on work efficiency, under manifold conditions, are incontrovertible. Some far-reaching conclusions from results of investigations into the hazards of noise are, cautiously, drawn by the author; among these may be cited: "The level of $90 \mathrm{~dB}$ is not too far from the level which has to be regarded as a threat to hearing; . . . if precautions are taken to prevent, deafness, they will also tend to prevent effects on working 
efficiency." "This level-90 dB-is not at all unusual in industry, but it is very much higher than the level which people often complain about in offices and other places away from the factory floor." As is common experience, undue noise makes normal conversation impossible; it is in fact difficult unless the noise is reduced well below the $90 . \mathrm{dB}$ level. $60 \mathrm{~dB}$ is considered a more reasonable level, but in an office environment, where ordinary speech is involved, the limits of noise should be much lower.

The question of noise in all its aspects, but particularly as a hazard in industry, is now a matter of national importance. It is indeed gratifying to learn that the Ministry of Pensions and National Insurance has sponsored a large-scale research project into certain aspects of occupational deafness. This is the joint problem of the Medical Research Council and the National Physical
Laboratory. "The purpose of this study is to monitor hearing of people exposed to industrial noise... to establish the relation between noise and damage to hearing . . . to make recommendations concerning hearing-conversation measures." When it is commonly roalized that effects of prolonged noise, in whatever environment, above a certain level, are real, and provocative of perman. ent deafness, then people may begin to take those precautions which common sense (and this booklet) suggest. Apart from this, undue and unwanted noise, especially when it intrudes into social life, public or private, without let or hindrance, is a form of annoyance which many people will not tolerate. The recent ban on transistor radio sets operating in some of Britain's royal parks is a step in the right direction. but only a beginning.

H. B. Milner

\title{
THE LISTER INSTITUTE
}

\begin{abstract}
$\mathrm{T}$ HE annual report of the Governing Body of the Lister Institute* is necessarily a greatly condensed account of the varied activities of 'The Lister', and it is impossible to indicate in a brief notice the scope and detail of the research involved. The report summarizes the Institute's work under several headings.

In the field of microbiology, work continues on the genetics of bacteria, particularly Salmonella spp., with special regard to the transmission of drug resistance; on the specificity of the antigens of Trypanosoma brucei and $T$. vivax, and on the conditions governing the formation of capsules by the anthrax bacillus in vitro. The Institute's field studies on trachoma in the Gambia continue, together with work on the epidemiology and pathology of pleuropneumonia-like organisms and of the Shope fibroma virus in cell culture. There has been continued progress in making a non-infectious smallpox vaccine and in work on the purification of vaccinia virus and antibody immunity in vaccinia and variola infections.

Among the epidemiological studies was an important investigation, carried out in co-operation with the Malaria Fradication Division of the World Health Organization and the Veterinary Services of Southern Rhodesia, of identification tests of the blood meals of tsetse flies and Anopheles mosquitoes.

Immunopathological investigations are being carried out on a factor in anaphylactic tissues which induces eosinophilia; on the local production in the cervix uteri of antibodies lethal to spermatozoa, and on improvement of therapeutic antitoxins to scorpion bites.

$T$. brucei, which had not been previously cultured for any prolonged period, has been successfully established in a liquid medium which makes it available for immunological and biochemical studies. Other work includes investigations of the immunology of whooping cough and typhoid and the mechanism of infection with actinomycotic dermatitis of sheep. The section devoted to the physiology

* The Lister Institute of Preventive Medicine. Report of the Governing Bordy, 1964. Pp. 37. (London: The Lister Institutc of Preventive Medicine,
1964.)
\end{abstract}

of bacteria includes studies of the somatic polysaceharides of S. and R. Salmonella and the chemistry of the flagellar proteins of Salmonella.

Biophysical work includes work on human plasma proteins and on the molecular characterizations of bloodgroup substances. The latter has led to extension and modification of existing theories for interpreting sedimentation and viscosity data. The Blood Products Laboratory continued to prepare dried plasma and plasma fractions for the National Health Service, and the Blood Group Research Unit has continued to study the $\mathrm{Xg}$ and the $\mathrm{Rh}$ systems. The Blood Group Reference Laboratory continues its work in its now building north of the Biophysies Department.

The report records the conferment of a baronetcy on the chairman of the Institute's Governing Body, Sir Charles Dodds, and the elections of Lord Iveagh and Lord Brain, both members of the Governing Body, to fellowship of the Royal Society. The death during the year of R. St. John Brooks, curator for more than 20 years of the National Collection of Type Cultures, is a great loss to the Institute and to microbiology in gencral. The director of the Institute, Prof. A. A. Miles, has been appointed Biological Secretary and a vice-president of the Royal Society of London. During the year the Guinness chair of microbiology was established at the Institute and Dr. B. A. D. Stocker was appointed to it.

A gift of $£ 30,000$ from the Fleming Memorial Fund for Medical Research will enable the Institute to establish its ewn dectron-microscope unit. The new Virus Laboratory at Elstree was completed during the year and occupied by the Virus Research Unit, and the Library at Chelsea was enlarged by the addition of another room.

The report also records the lectures given by the staff in Europe and America, and concludes with a list of their numerous publications.

For details of the biochemical work on blood-group substances, cellular phospholipids and glycogen the report itself must be consulted.
G. LAPAGE

\section{MOUSE ANTIBODY PRODUCTION TEST FOR THE ASSAY OF THE MOLONEY VIRUS}

\author{
By Dr. EVA KLEIN and Prof. GEORGE KLEIN \\ Department of Tumour Biology, Karolinska Institutet Medical School, Stockholm
}

TOCULATION of homografts, sub-threshold isografts or tissue homogenates derived from mouse lymphomas induced by the Moloney virus leads to specific transplantation resistance against subsequent Moloney lymphoma isografts ${ }^{1}$. The serum of resistant mice contains humoral antibodies, demonstrable in three different ways: by passive transfer of transplantation resistance, by cytotoxicity for Moloney Jymphoma cells in vitro in the 